\title{
A method of using the pulmonary trunk to form a trileaflet valve
}

\author{
Jennifer K. White, MD, ${ }^{a}$ Arvind K. Agnihotri, MD, ${ }^{a}$ Christian Latrémouille, MD, $\mathrm{PhD}^{\mathrm{c}, \mathrm{d}}$ \\ Emmanuel Messas, MD, ${ }^{\text {be }}$ Alain Carpentier, MD, PhD, ${ }^{\text {,ff }}$ and David F. Torchiana, MD, ${ }^{a}$ \\ Boston, Mass, and Paris, France
}

$\mathrm{R}$

eplacement heart valves constructed from autologous tissues have been attempted, with significant variations in long-term leaflet pliability and cellular viability. ${ }^{1-3}$ A new method of creating a potentially viable trileaflet valve from autologous pulmonary artery was investigated.

\section{Materials and Methods}

Human anatomic study. Using cadavers $(\mathrm{n}=7)$, the main pulmonary trunk was removed and trimmed to create a tissue cylinder with a height equal to the corresponding aortic annulus diameter (Figure 1, A). Three longitudinal incisions, $2 \mathrm{~mm}$ less than one half the cylinder height, were positioned $120^{\circ}$ apart (Figure 1, A). The resulting flaps were involuted and secured 2 to $3 \mathrm{~mm}$ from the superior rim of the cylinder with 6-0 polypropylene (Prolene; Ethicon, Inc, Somerville, NJ) sutures passed through adjacent flaps near their free edges and tied, making each a $U$ stitch (Figure 1, $B-D$ ). The base of the involuted tissue was joined with additional 6-0 polypropylene sutures, creating interleaflet triangles and eliminating acute corners from the inner surface of the valve (Figure 1,E). The outermost wall was scalloped (Figure 1, D and E).

Implantation was performed with a subcoronary, modified freehand method (Figure 1, $F$ and $G$ ). After removal of the native leaflets, stay sutures were passed through the aortic annulus at a position corresponding to the midpoint of each excised leaflet. These were placed through the construct at the superior cut edge (as opposed to the base of the valve in the freehand method), and the construct was lowered into position (Figure 1, F). A 6-0 polypropylene suture was run along the superior aspect of the construct's outermost wall, following the commissural pillars' contours (Figure 1, G). Passive testing of

\footnotetext{
From the Division of Cardiac Surgery ${ }^{\mathrm{a}}$ and Department of Cardiology, ${ }^{\mathrm{b}}$ Massachusetts General Hospital, Boston, Mass; the Institut d' Anatomie, UFR Biomédicale des Saints-Péres; the Departments of Cardiovascular Surgery ${ }^{\mathrm{d}}$ and Cardiology, ${ }^{\mathrm{e}}$ Hôpital European George Pompidou; and the Département de Chirurgie Cardio-vasculaire, ${ }^{\mathrm{f}}$ Hôpital Broussais, Paris, France.

Received for publication July 16, 2004; accepted for publication July 21, 2004.

Address for reprints: Jennifer K. White, MD, Division of Cardiac Surgery, Massachusetts General Hospital, Bullfinch 119/50 Fruit St, Boston, MA 02114 (E-mail: jkwhite@ partners.org).

J Thorac Cardiovasc Surg 2005;129:677-9

$0022-5223 / \$ 30.00$

Copyright $\odot 2005$ by The American Association for Thoracic Surgery

doi:10.1016/j.jtcvs.2004.07.030
}

each valve's competency was performed under a $200 \mathrm{~mm} \mathrm{Hg}$ saline column, enabling endo-

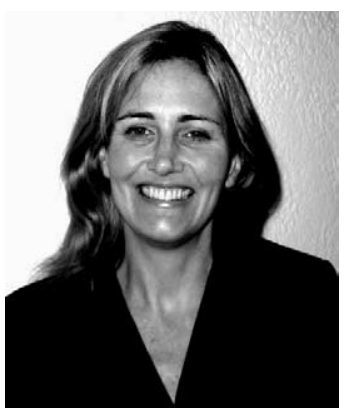

Dr White scopic inspection of the neoleaflets. One aortic root was positioned in a flow simulator, and transvalvular pressure gradients were determined across a range of flows (1-6 L/min, $0.9 \%$ saline).

Sheep study. The valve design was tested in an adult sheep model $(n=2)$. Before each operation, a replacement valve derived from the pulmonary trunk of a donor sheep was passively tested. The valve constructs were implanted as aortic valve replacements in the subcoronary position by the modified freehand technique described previously (Figure $1, F$ and $G$ ). After weaning from cardiopulmonary bypass, the valves were examined with an epicardial echocardiography probe. Regurgitant flow was determined by continuous-wave Doppler scanning in the long-axis view. Peak velocity was obtained in the one animal in which anatomic alignment of the probe allowed measurement. All animals received humane care in compliance with the "Guide for the Care and Use of Laboratory Animals"4 prepared by the Institute of Laboratory Resources, National Research Council.

\section{Results}

In $5(71 \%)$ of the 7 cadavers, there was sufficient pulmonary artery trunk tissue to construct competent aortic valve replacements by the involution method (pulmonary trunk diameter, $23.7 \pm 3.3 \mathrm{~mm}$; pulmonary trunk length, $24.9 \pm 3.7 \mathrm{~mm}$; aortic annulus diameter, $21.6 \pm 2.7 \mathrm{~mm}$ ) (Figure 2). Under passive testing, these 5 valves displayed symmetric 3-leaflet coaptation with no central orifice at closure.

The human valve construct positioned in the flow simulator had a transvalvular pressure gradient of 1 to $3 \mathrm{~mm} \mathrm{Hg}$ across a range of flows 1 to $6 \mathrm{~L} / \mathrm{min}$ without evidence of acute angle bending of the leaflet bases during leaflet opening. Both sheep implants demonstrated mild aortic regurgitation with symmetric and pliable leaflet mobility throughout the cardiac cycle. A peak pressure gradient of $25 \mathrm{~mm} \mathrm{Hg}$ was calculated by using the modified Bernoulli equation (peak velocity of $2.49 \mathrm{~m} / \mathrm{s}$ ) in one animal with a 14-mm aortic annulus diameter.

\section{Discussion}

Previous reports have described use of the autologous pulmonary artery to create valve substitutes. The monocusp pulmonary valve replacement has been used clinically in pediatric patients undergoing Ross procedures. ${ }^{5}$ In another method, a segment of the pulmonary trunk was implanted in the subcoronary position and 


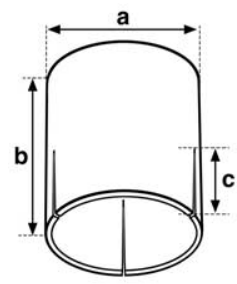

A

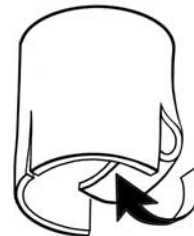

B
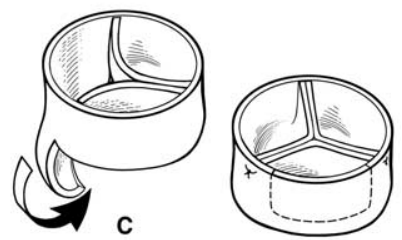

D
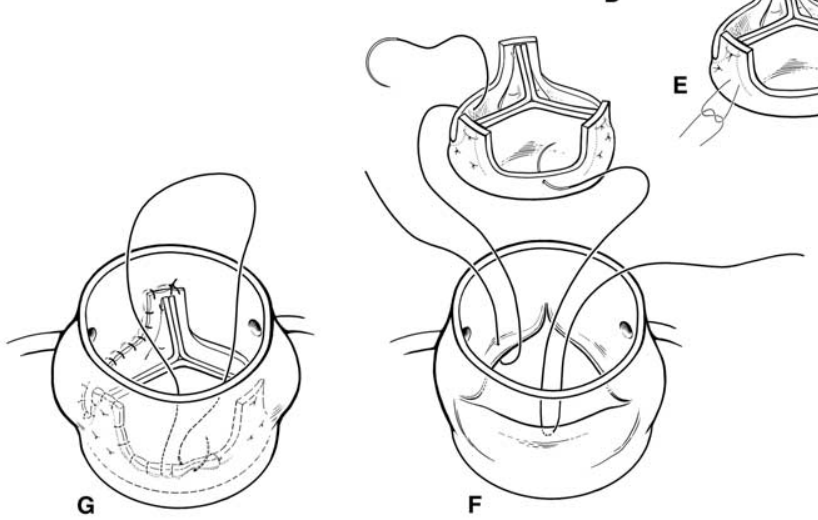

Figure 1. Involution method of valve construction and surgical implantation. A segment of the pulmonary artery trunk was harvested and trimmed to a length (b) equal to the diameter of the corresponding aortic annulus. Three longitudinal incisions, positioned $120^{\circ}$ apart, were created such that the length (c) of each incision was slightly less than one half the cylinder height $(b ; A)$. The resulting tissue flaps were involuted into the cylinder (B and C). Sutures were passed through adjacent flaps and secured as $\mathbf{U}$ stitches near the superior rim of the tissue cylinder (D). Additional $\mathrm{U}$ stitches secured the base of the involuted tissue to the outer cylinder, creating interleaflet triangles $(E)$. The construct wall between the commissures was scalloped ( $D$ and $E$ ). Implantation of the valve was performed with a modified freehand technique, in which stay sutures are passed between the aortic annulus and the superior cut edge of the valve construct $(F)$. After the construct had been lowered into the subcoronary position, a continuous 5-0 polypropylene suture was run along the superior aspect of the construct's outermost wall (G).

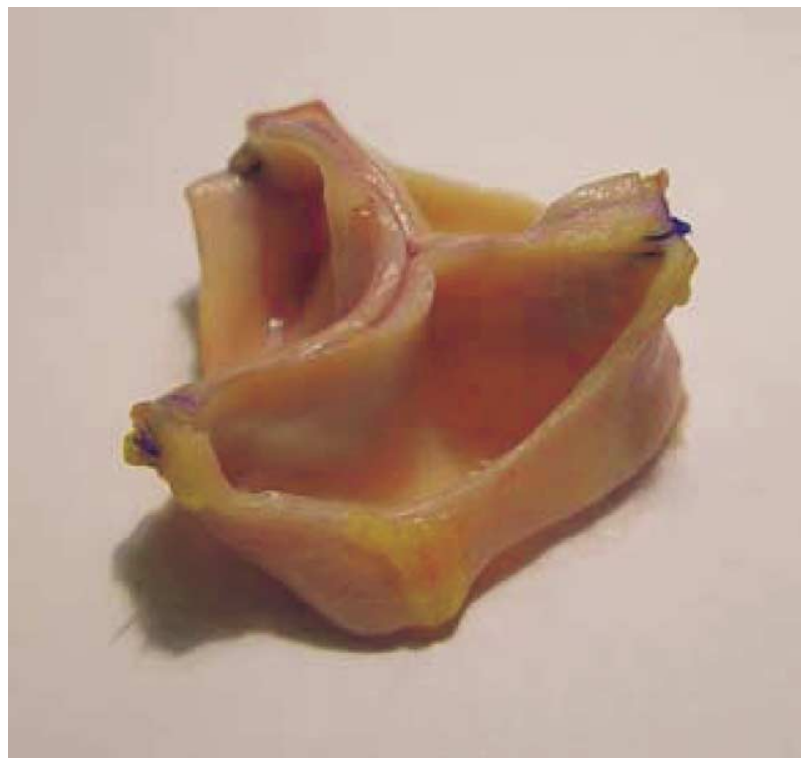

Figure 2. Photograph of valve construct derived from human pulmonary artery by the involution method. secured at 3 points to create a trileaflet aortic valve replacement. ${ }^{6}$ Concerns regarding surgical reproducibility and durability, particularly in the aortic position, have limited widespread clinical application.

This study describes an efficient autologous tissue valve construction method that offers several potential advantages: it might be more reproducible because construction occurs before implantation and more versatile because it can be transplanted to other implant sites. As an aortic valve replacement, it might circumvent the surgical risks and complications associated with a valve switch, in part by preserving the native pulmonary valve. Alternatively, it might offer a more suitable pulmonic valve replacement option other than a homograft or moncusp during a Ross procedure. Further investigations, including long-term animal studies, would be useful to assess the clinical feasibility of this valve construct in human patients.

\section{References}

1. Bailey CP, Carstens HP, Zimmerman J, Hirose T. Aortic valve replacement with autogenous aortic wall. Am J Cardiol. 1965;15: 367-79. 
2. Senning Å. Alterations in valvular surgery: biologic valve. In: Cohn LH, Gallucci V, editors. Cardiac bioprostheses: proceedings of the second international symposium on cardiac bioprostheses. New York: Yorke Medical Books; 1982. p. 140-53.

3. Love JW. Biological and engineering problems of tissue heart valves. In: Love JW, editor. Autologous tissue heart valves. Austin (TX): R. G. Landes, Inc; 1993. p. 25-31.
4. Guide for the care and use of laboratory animals. Washington (DC): National Academy Press; 1996.

5. Couetil JA, Berrebi A, Ferdinand FD, Fornes P, Adamopoulos C, Filsoufi F. New approach for reconstruction of the pulmonary outflow tract during the Ross procedure. Circulation. 1998;98(suppl II):II368-71.

6. Hvass U. Aortic valve replacement in children using a pulmonary artery wall [in French]. Presse Med. 1985;14:1926-7.

\title{
Stapled excision of the left atrial appendage
}

\author{
A. Marc Gillinov, MD, Gosta Pettersson, MD, PhD, and Delos M. Cosgrove III, MD, Cleveland, Ohio
}

$\mathrm{T}$

he left atrial appendage (LAA) has been termed "our most lethal human attachment." ${ }^{1}$ Excision or exclusion of the LAA is a component of most operations to treat atrial fibrillation (AF) and reduces late thromboemboli in patients with $\mathrm{AF}$ undergoing mitral valve surgery. ${ }^{2}$ However, surgical technique affects results, and incomplete suture ligation increases risk of thromboembolism. ${ }^{2,3}$ We report our experience with stapled excision and pericardial buttressing of the LAA.

\section{Methods}

From January 2002 through December 2004, several suture and stapling techniques were used to excise the LAA in more than 500 patients. Incomplete ligation and recanalization with suture techniques and bleeding with unbuttressed staplers led us to the procedure described here.

Before manipulation of the heart, the LAA is examined by intraoperative transesophageal echocardiography. If there is thrombus, standard cut-and-sew technique is used to excise the LAA. Otherwise, after cardioplegic arrest the Endo GIA II stapler (United States Surgical Corporation, Norwalk, Conn) with $4.8-\mathrm{mm}$ staples is used to excise the LAA. Bovine pericardial strips (Peri-Strips Dry; Synovis Surgical Innovations, St Paul, Minn) buttress the staple line. The stapler is positioned parallel to the base of the LAA and 3 to $5 \mathrm{~mm}$ from the

\footnotetext{
From the Department of Thoracic and Cardiovascular Surgery, The Cleveland Clinic Foundation, Cleveland, Ohio.

Received for publication July 9, 2004; revisions received July 13, 2004; accepted for publication July 21, 2004.

Address for reprints: A. Marc Gillinov, MD, Department of Thoracic and Cardiovascular Surgery, The Cleveland Clinic Foundation, 9500 Euclid Ave, Cleveland, OH 44195 (E-mail: gillinom@ccf.org).

J Thorac Cardiovasc Surg 2005;129:679-80

$0022-5223 / \$ 30.00$

Copyright $\odot 2005$ by The American Association for Thoracic Surgery

doi:10.1016/j.jtcvs.2004.07.039
}

circumflex coronary artery, leaving a buttressed staple line on the heart (Figure 1). The staple line and the region beneath the staple line are examined for tears; any tears are repaired with pledget-supported suture. Hospital charges are $\$ 317$ for the stapler and $\$ 246$ for buttressing material.

\section{Results}

This buttressed stapling technique was used for LAA excision in 222 patients. The most common indication for surgery was mitral valve dysfunction (78\%); in addition, $90 \%$ of patients underwent a procedure for AF. Patients undergoing AF ablation received 3 months of postoperative warfarin. All patients underwent both intraoperative and predischarge echocardiograms.

There was no staple line bleeding; however, $10 \%$ of patients required additional sutures beneath the staple line to repair tears. There were 5 perioperative strokes $(2 \%)$. In 1 of these patients, there was laminar left atrial thrombus adjacent to a mitral bioprosthesis. No other patient had left atrial thrombus seen on predischarge echocardiography. Reoperation for bleeding was required in 7 cases $(3 \%)$. In no case was the LAA the source of bleeding.

\section{Discussion}

In patients with $\mathrm{AF}, 90 \%$ of emboli responsible for strokes arise from the LAA. ${ }^{1}$ It has been suggested that ligation of the LAA reduces the risk of stroke in cardiac surgical patients with and without preexisting AF. ${ }^{1,2,4}$ A variety of techniques have been used for excision or exclusion of the LAA, but there are few surgical devices designed specifically for this purpose. ${ }^{1,2,4,5}$

Suture ligation of the LAA is frequently incomplete, leaving a communication that increases the risk of embolism. ${ }^{2,3}$ Noncutting staplers may be used to exclude the LAA; however, staple lines frequently bleed, and we have observed late recanalization of the lumen. Cutting staplers ensure excision of the trabeculated portion of the LAA, and pericardial buttressing prevents staple line bleeding; however, fragile tissue beneath the staple line may tear. Our current practice is to use a cutting stapler with pericardial buttressing for excision of the LAA. As instrumentation improves, we anticipate extension of LAA excision or exclusion to virtually all patients undergoing cardiac surgery. 